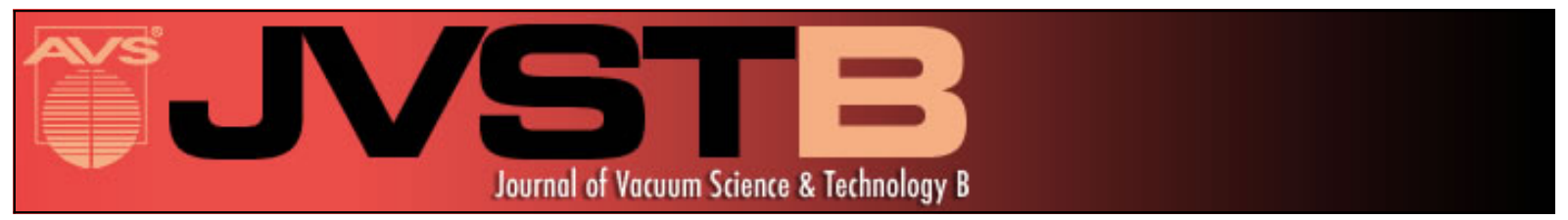

\title{
GaSb based midinfrared equilateral-triangle-resonator semiconductor lasers
}

S.-Q. Yu, Y. Cao, S. R. Johnson, Y.-H. Zhang, and Y.-Z. Huang

Citation: Journal of Vacuum Science \& Technology B 26, 56 (2008); doi: 10.1116/1.2819260

View online: http://dx.doi.org/10.1116/1.2819260

View Table of Contents: http://scitation.aip.org/content/avs/journal/jvstb/26/1?ver=pdfcov

Published by the AVS: Science \& Technology of Materials, Interfaces, and Processing

Articles you may be interested in

Publisher's Note: "Two-layer photo-thermal deflection model to study the non-radiative recombination process:

Application to Ga0.7In0.3As0.23Sb0.77/GaSb and Al0.3Ga0.7As0.08Sb0.92/GaSb laser structures" [J. Appl.

Phys. 113, 183705 (2013)]

J. Appl. Phys. 113, 239902 (2013); 10.1063/1.4811543

$200 \mathrm{~mW}$ type I GaSb-based laser diodes operating at $3 \mu \mathrm{m}$ : Role of waveguide width

Appl. Phys. Lett. 94, 261104 (2009); 10.1063/1.3159819

Room-temperature external cavity GaSb-based diode laser around $2.13 \mu \mathrm{m}$

Appl. Phys. Lett. 85, 5825 (2004); 10.1063/1.1833561

Measurements of optical losses in mid-infrared semiconductor lasers using Fabry-Pérot transmission oscillations J. Appl. Phys. 95, 7584 (2004); 10.1063/1.1738523

Molecular beam epitaxial growth of mid-infrared InGaAsSb laser diodes on indium-free GaSb substrates J. Vac. Sci. Technol. B 22, 1460 (2004); 10.1116/1.1740768

\section{SHIMADZU Powerful, Multi-functional UV-Vis-NIR and Excellence in Science FTIR Spectrophotometers}

Providing the utmost in sensitivity, accuracy and resolution for applications in materials characterization and nano research

- Photovoltaics

- Polymers

- Thin films

- Paints

- Ceramics

- DNA film structures

- Coatings

- Packaging materials

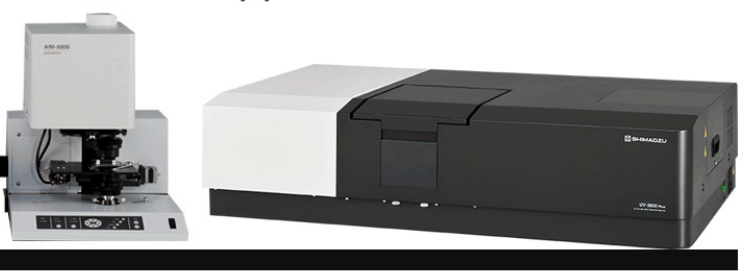




\title{
GaSb based midinfrared equilateral-triangle-resonator semiconductor lasers
}

\author{
S.-Q. Yu, ${ }^{\text {a) }}$ Y. Cao, S. R. Johnson, and Y.-H. Zhang \\ Center for Solid State Electronics Research and Department of Electrical Engineering, Arizona State \\ University, Tempe, Arizona 85287-6206 \\ Y.-Z. Huang \\ State Key Laboratory on Integrated Optoelectronics, Institute of Semiconductors, \\ Chinese Academy of Sciences, Beijing 100083, People's Republic of China
}

(Received 21 September 2007; accepted 5 November 2007; published 3 January 2008)

\begin{abstract}
Theoretical calculations of the mode characteristics of an equilateral-triangle resonator (ETR) with a $10 \mu \mathrm{m}$ cavity side length show that the fundamental mode, with longitudinal mode index of 25 , has a wavelength of $2.185 \mu \mathrm{m}$ and a longitudinal mode separation of $100 \mathrm{~nm}$. This mode has a quality factor $\left(\sim 2 \times 10^{5}\right)$ that is much larger than the first $\left(\sim 5 \times 10^{4}\right)$ and second $\left(\sim 3 \times 10^{4}\right)$ order modes, indicating that single fundamental mode lasing should be accessible over a broad wavelength tuning range. An electrically injected ETR based on this design is fabricated from an $\mathrm{InGaAsSb} / \mathrm{AlGaAsSb} / \mathrm{GaSb}$, graded-index separate-confinement heterostructure, laser diode wafer with a $2.1 \mu \mathrm{m}$ emission wavelength. This device achieved single mode, continuous wave operation at $77 \mathrm{~K}$ with a threshold current of $0.5 \mathrm{~mA}$ and a single mode wavelength tuning range of $3.25 \mathrm{~nm}$, which is accomplished by varying the injection current from 0.5 to $6.0 \mathrm{~mA}$. (C) 2008 American Vacuum Society. [DOI: 10.1116/1.2819260]
\end{abstract}

\section{INTRODUCTION}

Spectroscopic gas detection techniques have many applications in environmental protection such as air pollution monitoring. ${ }^{1-3}$ Even though Fourier transform infrared (FTIR) spectroscopy has been widely adapted in these areas because of its broad spectrum coverage, high resolution, and quick response, tunable laser absorption spectroscopy (TLAS) is gaining more and more acceptance due to its potential to achieve integrated, compact, and in situ monitoring capabilities. ${ }^{4,5}$ The key component of a TLAS system for air pollution monitoring is a single mode midinfrared $(2-3 \mu \mathrm{m})$ laser diode with a broad wavelength tuning range.

Semiconductor lasers incorporating InGaAsSb/ $\mathrm{AlGaAsSb}$ quantum well (QW) active regions grown on GaSb substrates are ideal candidates for this application. This active material is well developed for light emission over the 2-3 $\mu \mathrm{m}$ range, and high performance GaSb based edgeemitting lasers (EELs) with low threshold and high power output have been demonstrated. ${ }^{6,7}$ Obtaining a single mode device with low fabrication costs is nontrivial. Currently, distributed-feedback lasers have to be fabricated using costly electron-beam-lithography technology to define the grating. ${ }^{8}$ Semiconductor single mode microdisk lasers are easy to fabricate but have the major drawback of low laser light extraction efficiency. ${ }^{9}$ Short cavity Fabry-Pérot lasers can have longitudinal mode spacing wider than the gain spectrum, and therefore, can achieve single mode operation when one mode overlaps the gain spectrum. However, forming a laser cavity

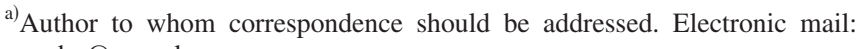
yushq@asu.edu shorter than $100 \mu \mathrm{m}$, which is still not short enough to obtain single mode operation, is difficult using conventional cleaving technology.

Recent theoretical work shows that semiconductor lasers utilizing an equilateral-triangle-resonator (ETR) integrated with a waveguide connected to one vertex of the resonator can provide both large mode separation and directional light emission. $^{10-12}$ Therefore, a GaSb based ETR laser offers a low cost solution as a TLAS light source. In this paper the growth, fabrication, and characterization are reported for four high-quality EEL devices utilizing the InGaAsSb/AlGaAsSb/GaSb material system with emission wavelengths from 2.1 to $3.1 \mu \mathrm{m}$. The laser material with $2.1 \mu \mathrm{m}$ emission is chosen for the fabrication of electrically injected ETR lasers that have a $10 \mu \mathrm{m}$ side length.

\section{InGaAsSb/AIGaAsSb QW LASER MATERIAL GROWTH AND CHARACTERIZATION}

The materials were grown on $n$-type (100) GaSb substrates using a VG V80H solid source molecular beam epitaxy machine equipped with $\mathrm{Ga}$, In, and $\mathrm{Al}$ group-III sources, $\mathrm{Si}, \mathrm{Be}$, and Te dopant sources, and $\mathrm{As}, \mathrm{Sb}$, and $\mathrm{P}$ valved cracker group- $\mathrm{V}$ sources. The bulk zone and the cracking zone of group- $\mathrm{V}$ sources are held at constant temperatures and automated valve controllers are used to control the group- $\mathrm{V}$ fluxes.

The EEL structure consists of a graded-index separateconfinement heterostructure with a triple InGaAsSb/AlGaAsSb QW active region. The laser structure starts with a $300 \mathrm{~nm}$ thick Te-doped $\left(n=5 \times 10^{17} \mathrm{~cm}^{-3}\right)$ GaSb buffer layer, followed by a $200 \mathrm{~nm}$ thick Te-doped $\left(n=5 \times 10^{17} \mathrm{~cm}^{-3}\right) \quad$ layer graded from $\mathrm{GaSb}$ to $\mathrm{Al}_{0.90} \mathrm{Ga}_{0.10} \mathrm{As}_{0.08} \mathrm{Sb}_{0.92}$, and a $1.8 \mu \mathrm{m}$ thick Te-doped $(n=5$ 
TABLE I. A summary of active region structures and characterization results for devices A, B, C, and D; all measurements were done under pulsed operation. (Notation: $E_{g}$ is the band gap energy of the QW material; $\Delta E_{C} / \Delta E_{V}$ is the conduction/valence band discontinuity between the QW barrier and the QW; $L / W$ is the device cavity length/stripe width; $I_{\text {th }}$ is the threshold current density; $T_{\max }$ is the maximum lasing temperature; and $T_{0}$ is the characteristic temperature.)

\begin{tabular}{|c|c|c|c|c|}
\hline Device & A & B & $\mathrm{C}$ & $\mathrm{D}$ \\
\hline QW & $\mathrm{In}_{0.15} \mathrm{Ga}_{0.85} \mathrm{As}_{0.06} \mathrm{Sb}_{0.94}$ & $\mathrm{In}_{0.50} \mathrm{Ga}_{0.50} \mathrm{As}_{0.25} \mathrm{Sb}_{0.75}$ & $\mathrm{In}_{0.50} \mathrm{Ga}_{0.50} \mathrm{As}_{0.25} \mathrm{Sb}_{0.75}$ & $\mathrm{In}_{0.60} \mathrm{Ga}_{0.40} \mathrm{As}_{0.35} \mathrm{Sb}_{0.65}$ \\
\hline $\begin{array}{l}\text { QW } \\
\text { Barrier }\end{array}$ & $\mathrm{Al}_{0.25} \mathrm{Ga}_{0.75} \mathrm{As}_{0.02} \mathrm{Sb}_{0.98}$ & $\mathrm{Al}_{0.25} \mathrm{Ga}_{0.75} \mathrm{As}_{0.02} \mathrm{Sb}_{0.98}$ & $\mathrm{Al}_{0.40} \mathrm{Ga}_{0.60} \mathrm{As}_{0.03} \mathrm{Sb}_{0.97}$ & $\mathrm{Al}_{0.40} \mathrm{Ga}_{0.60} \mathrm{As}_{0.03} \mathrm{Sb}_{0.97}$ \\
\hline$E_{g}(\mathrm{meV})$ & 590 & 440 & 440 & 400 \\
\hline $\begin{array}{l}\Delta E_{C} \\
(\mathrm{meV})\end{array}$ & 387 & 630.9 & 756.9 & 848.7 \\
\hline $\begin{array}{l}\Delta E_{V} \\
(\mathrm{meV})\end{array}$ & 86 & 15.5 & 82.1 & 30.3 \\
\hline$\lambda(\mu \mathrm{m})$ & 2.1 & 2.8 & 2.8 & 3.1 \\
\hline$L / W(\mu \mathrm{m})$ & $830 / 50$ & $825 / 50$ & $805 / 50$ & $1800 / 50$ \\
\hline $\begin{array}{l}J_{\text {th }} \\
\left(\mathrm{A} / \mathrm{cm}^{2}\right)\end{array}$ & 181 & 533 & 497 & 4370 \\
\hline$T_{\max }\left({ }^{\circ} \mathrm{C}\right)$ & 125 & 40 & 65 & 25 \\
\hline$T_{0}(\mathrm{~K})$ & 76 & 33 & 62 & 26 \\
\hline $\begin{array}{l}\text { cw (duty } \\
\text { cycle) }\end{array}$ & Yes & No $(12.5 \%)$ & Yes & No $(1 \%)$ \\
\hline
\end{tabular}

$\left.\times 10^{17} \mathrm{~cm}^{-3}\right) \quad \mathrm{Al}_{0.90} \mathrm{Ga}_{0.10} \mathrm{As}_{0.08} \mathrm{Sb}_{0.92}$ lower cladding layer. The triple QW active regions are comprised of three compressively strained 8-12 $\mathrm{nm}$ thick InGaAsSb QWs separated by $20 \mathrm{~nm}$ thick low Al-content AlGaAsSb barriers and are sandwiched between two 250-350 nm thick low Al-content AlGaAsSb waveguide layers. There are two $100 \mathrm{~nm}$ thick, undoped, linearly graded-index regions on either side of the waveguide layers. The In and Al concentrations in the active region are varied to achieve the various target emission wavelengths. The waveguide region is followed by a $1.8 \mu \mathrm{m}$ thick Be-doped $\left(p=5 \times 10^{17} \mathrm{~cm}^{-3}\right) \quad \mathrm{Al}_{0.90} \mathrm{Ga}_{0.10} \mathrm{As}_{0.08} \mathrm{Sb}_{0.92}$ upper cladding layer, a $200 \mathrm{~nm}$ thick Be-doped $(p=5$ $\times 10^{17} \mathrm{~cm}^{-3}$ ) layer graded from $\mathrm{Al}_{0.90} \mathrm{Ga}_{0.10} \mathrm{As}_{0.08} \mathrm{Sb}_{0.92}$ to $\mathrm{GaSb}$, and a $100 \mathrm{~nm}$ thick Be-doped $\left(p^{+}\right) \mathrm{GaSb}$ contact layer. A $20 \mathrm{~nm}$ thick undoped sacrificial InAs cap layer is grown on top of the $p^{+} \mathrm{GaSb}$ contact layer to prevent oxidation of the layers underneath. The InAs layer is selectively etched away with citric acid during device processing.

The growth temperatures are $525{ }^{\circ} \mathrm{C}$ for the bottom cladding layer and $485^{\circ} \mathrm{C}$ for the active region and the top cladding layer; relatively low growth temperatures are employed to minimize In and Sb interdiffusion in the InGaAsSb QWs. The Sb/III flux ratio was kept constant at 1.25 , while the As/III flux ratio was varied to control the group-V mole fraction in the QWs and the thick lattice-matched AlGaAsSb layers. The composition of the cladding layers, QWs, and QW barriers was calibrated using high resolution x-ray diffraction and photoluminescence (PL) measurements prior to the growth of laser structures.

Broad contact EEL devices were fabricated using standard photolithography, wet etching, and metal deposition; after which device performance was measured to characterize the material quality. The as-cleaved devices were mounted $p$ side up on a thermoelectrically controlled metal stage for tem- perature dependent continuous wave (cw) and pulse measurements. The output power from one facet was monitored using a calibrated $\mathrm{PbS}$ photodetector, and the lasing spectra were measured using a Nicolet 760 FTIR spectrometer equipped with a $\mathrm{CaF}_{2}$ beam splitter, a liquid nitrogen cooled InSb photodetector, and $0.125 \mathrm{~cm}^{-1}$ spectra resolution.

The four devices $(\mathrm{A}, \mathrm{B}, \mathrm{C}$, and $\mathrm{D}$ with respective lasing wavelengths of $2.0,2.8,2.8$, and $3.1 \mu \mathrm{m}$ ) were measured under pulsed operation at room temperature. A complete summary of the device active region structures and characteristics is given in Table I. Among the four devices, device $\mathrm{A}$ (with $\mathrm{In}_{0.15} \mathrm{Ga}_{0.85} \mathrm{As}_{0.06} \mathrm{Sb}_{0.94} / \mathrm{Al}_{0.25} \mathrm{Ga}_{0.75} \mathrm{As}_{0.02} \mathrm{Sb}_{0.98} \mathrm{QWs}$ and $\mathrm{Al}_{0.25} \mathrm{Ga}_{0.75} \mathrm{As}_{0.02} \mathrm{Sb}_{0.98}$ waveguide layers) demonstrated the lowest threshold current density $\left(J_{\mathrm{th}}=181 \mathrm{~A} / \mathrm{cm}^{2}\right)$, the highest lasing temperature $\left(T_{\max }=125^{\circ} \mathrm{C}\right)$, and highest characteristic temperature $\left(T_{0}=76^{\circ} \mathrm{C}\right)$, all measured under pulsed operation. This device also achieved room temperature $\mathrm{cw}$ operation with peak output powers up to $8.5 \mathrm{~mW}$ and a maximum operating temperature of $50{ }^{\circ} \mathrm{C}$. The $\mathrm{cw}$ operation $L-I$ curve and multimode lasing spectra (at three times threshold) are shown in Fig. $1(\mathrm{a}) ; J_{\mathrm{th}}=313 \mathrm{~A} / \mathrm{cm}^{2}$ and the peak wavelength is $2.105 \mu \mathrm{m}$.

Both devices B and $\mathrm{C}$ are designed to lase at $2.8 \mu \mathrm{m}$ and both utilize $\mathrm{In}_{0.50} \mathrm{Ga}_{0.50} \mathrm{As}_{0.25} \mathrm{Sb}_{0.75} \mathrm{QWs}$ in the active region. The Al composition of the barrier/waveguide layer is lower in device $\mathrm{B}\left(\mathrm{Al}_{0.25} \mathrm{Ga}_{0.75} \mathrm{As}_{0.02} \mathrm{Sb}_{0.98}\right)$ and higher in device $\mathrm{C}$ $\left(\mathrm{Al}_{0.40} \mathrm{Ga}_{0.60} \mathrm{As}_{0.03} \mathrm{Sb}_{0.97}\right)$. The pulsed operation characteristics of device $\mathrm{B}$ are $J_{\text {th }}=533 \mathrm{~A} / \mathrm{cm}^{2}, T_{\max }=40^{\circ} \mathrm{C}$, and $T_{0}=33 \mathrm{~K}$, with lasing maintained up to a duty cycle of $12.5 \%$, while for device $\mathrm{C}, J_{\mathrm{th}}=497 \mathrm{~A} / \mathrm{cm}^{2}, T_{\max }=65^{\circ} \mathrm{C}$, and $T_{0}=62 \mathrm{~K}$, with lasing maintained all the way up to $\mathrm{cw}$ operation. Device D contains $\operatorname{In}_{0.60} \mathrm{Ga}_{0.40} \mathrm{As}_{0.35} \mathrm{Sb}_{0.65} \mathrm{QWs}$ with $\mathrm{Al}_{0.40} \mathrm{Ga}_{0.60} \mathrm{As}_{0.03} \mathrm{Sb}_{0.97}$ barrier/waveguide layers. By introducing additional In into the QW, the lasing wavelength is 

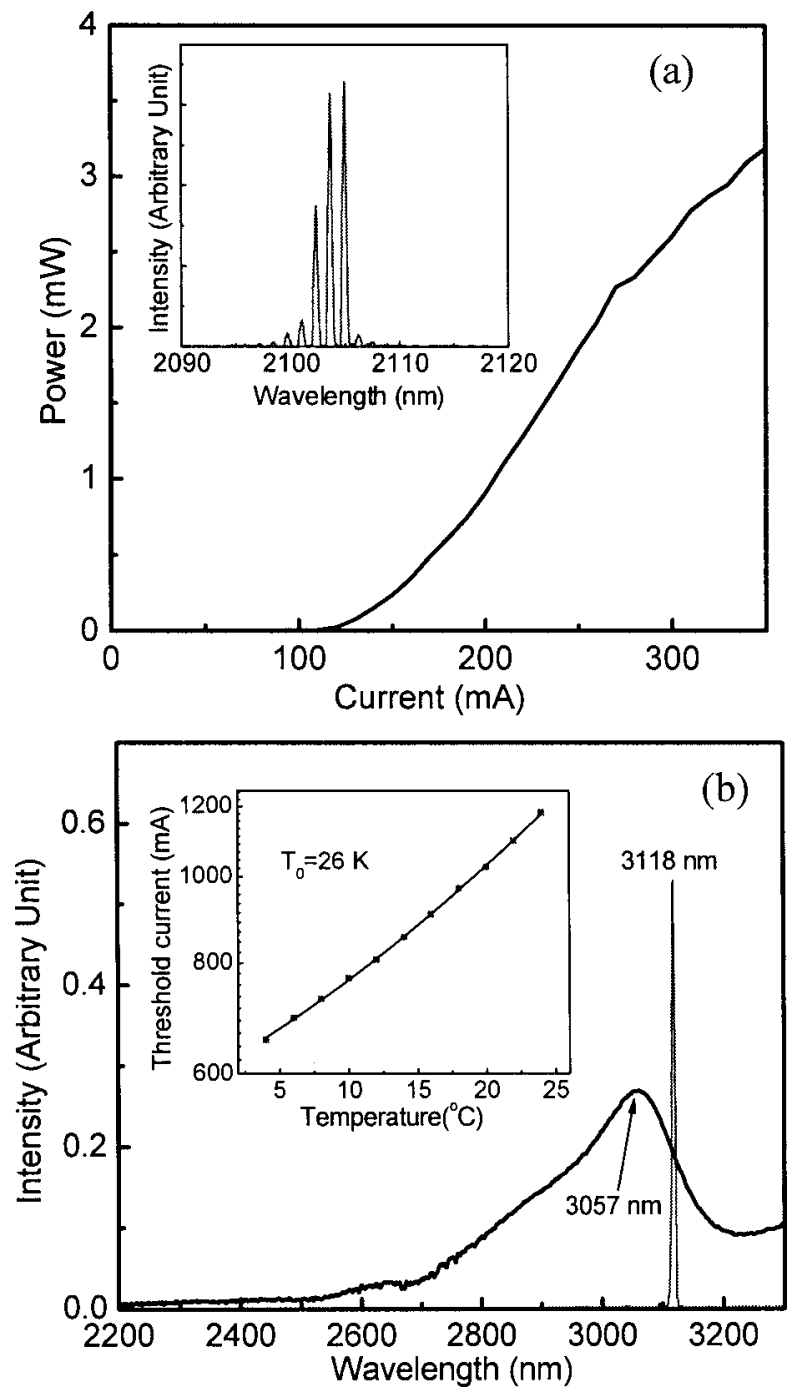

FIG. 1. (a) Typical $L-I$ characteristic for device A measured under cw operation, where the cavity length is $L=830 \mu \mathrm{m}$ and stripe width is $W=50 \mu \mathrm{m}$. The inset gives the lasing spectra just above threshold. (b) Room temperature PL and lasing spectra for device D. Inset gives pulsed threshold current vs temperature from 4 to $24{ }^{\circ} \mathrm{C}$, which is used to extract $T_{0}=26 \mathrm{~K}$.

pushed out to $3.1 \mu \mathrm{m}$. However, performance is reduced and the device only lased under pulsed operation with $J_{\text {th }}=4370 \mathrm{~A} / \mathrm{cm}^{2}, T_{\max }=25^{\circ} \mathrm{C}$, and $T_{0}=26 \mathrm{~K}$, with lasing maintained up to a duty cycle of $1 \%$ for a long cavity device $(1800 \mu \mathrm{m})$. The room temperature PL and lasing spectrum of device D with peak wavelengths of 3057 and $3118 \mathrm{~nm}$, respectively, are given in Fig. 1(b). The inset shows the lasing threshold current versus temperature measured from 4 to $24{ }^{\circ} \mathrm{C}$ for the purpose of extracting $T_{0}$. The $3.1 \mu \mathrm{m}$ lasing wavelength is close to the reported longest wavelength achieved by devices using this material system. ${ }^{13,14}$

The substantial increase in threshold current density $\left(J_{\text {th }}\right)$ from device A to devices $\mathrm{B}$ and $\mathrm{C}$ is attributed to the increasing Auger recombination with decreasing band gap energy. The improved device temperature performance from device $\mathrm{B}$ to $\mathrm{C}$ is due to improved carrier confinement in the active region. For device B, even though the band gap of

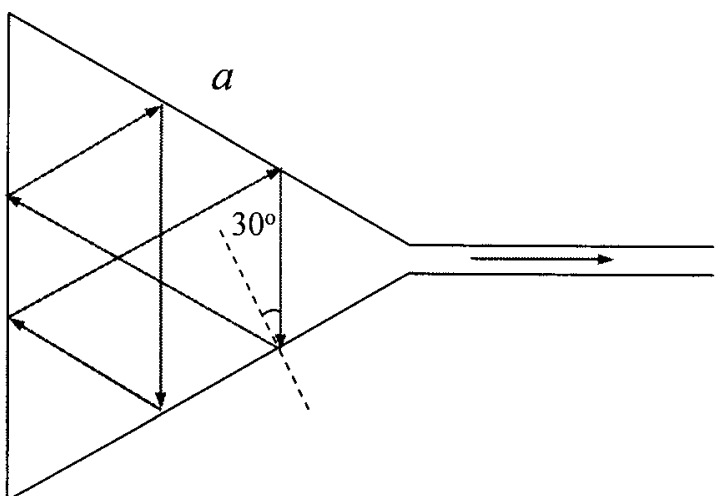

(a)

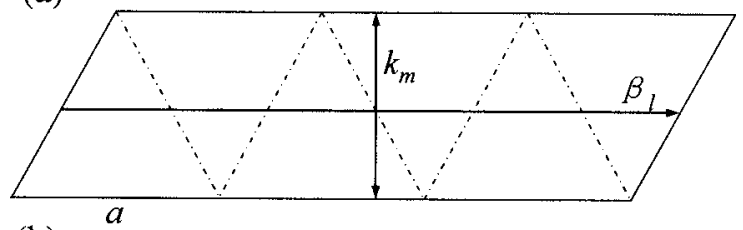

(b)

FIG. 2. (a) Schematic drawing of an ETR with an outcoupling waveguide. The arrows indicate the propagation of longitudinal modes in the folded cavity. (b) Schematic diagram of the corresponding Fabry-Pérot cavity with an unfolded light ray; both wave vectors $\beta_{l}$ and $k_{m}$ in the longitudinal and lateral directions are shown.

$\mathrm{Al}_{0.25} \mathrm{Ga}_{0.75} \mathrm{As}_{0.02} \mathrm{Sb}_{0.98}(1.086 \mathrm{eV})$ is much larger than that of $\operatorname{In}_{0.50} \mathrm{Ga}_{0.50} \mathrm{As}_{0.25} \mathrm{Sb}_{0.75}(0.440 \mathrm{eV})$, over $97 \%$ of the band offset is in the conduction band. This leaves a valence band offset of only $15.5 \mathrm{meV}$ which is smaller than the thermal energy $(25.8 \mathrm{meV})$ at room temperature. Since the shallow hole well can only provide weak confinement, poor thermal performance is expected due to carrier leakage followed by nonradiative recombination in the cladding layer. When the $\mathrm{Al}$ composition in the QW barrier is increased from 0.25 to 0.40 (device $\mathrm{C}$ ), the valence band discontinuity increases to $83 \mathrm{meV}$, providing much better confinement of the holes and hence improving thermal performance. This could also explain why device $\mathrm{C}$ achieved room temperature $\mathrm{cw}$ operation, while device $\mathrm{B}$ only achieved pulsed operation up to a duty cycle of $12.5 \%$.

In order to extend the laser emission to even longer wavelengths in device $\mathrm{D}$, additional In was incorporated into the active region. However, besides material quality degradation due to higher strain and increased narrow-band-gap Auger recombination, poor hole confinement may also be a major contributing factor to poor performance (high $J_{\text {th }}$, low $T_{\max }$ and $T_{0}$ ); the $\operatorname{In}_{0.60} \mathrm{Ga}_{0.40} \mathrm{AsSb} / \mathrm{Al}_{0.40} \mathrm{Ga}_{0.60} \mathrm{As}_{0.03} \mathrm{Sb}_{0.97} \mathrm{QWs}$ only have a $30.3 \mathrm{meV}$ valence band discontinuity, which is similar to that of device $\mathrm{B}$.

\section{ETR CAVITY DESIGN}

A schematic drawing of the ETR with an output coupling waveguide on one vertex is given in Fig. 2(a). Based on Snell's law, a light ray propagating parallel to the side of the ETR cavity will experience total internal reflection if the refractive index of the semiconductor is grater than 2.0 as is 
the case for all common semiconductors. As shown in Fig. 2(a), a particular given light ray can return to the starting point after a total of six reflections, resulting in a laser cavity length equal to the perimeter of the ETR cavity. By unfolding the light rays inside the ETR cavity as shown in Fig. 2(b), the ETR cavity can be modeled as a Fabry-Pérot cavity with two tilted facets, which provide $100 \%$ total reflection for laser oscillation in an ideal case. The optical field transmission is represented by the wave vectors $\beta_{l}$ and $k_{m}$ in the longitudinal and lateral directions, respectively. ${ }^{11}$ The incident angle on the sides of the ETR for the fundamental transverse mode is larger than that for the higher order transverse modes. Therefore, the ETR cavity has a strong mode selection for the fundamental mode over high order modes. ${ }^{11}$

Based on the cross section of the InGaAsSb/AlGaAsSb EELs described above, the equivalent refractive index $n$ in the transverse direction is determined to be 3.4. The longitudinal mode separations of the fundamental, first, and second order lateral modes in the ETR cavity are calculated ${ }^{11}$ and shown in Fig. 3(a). The different phase shifts for even and odd transverse modes induced by the total reflections at the ETR sides result in a large wavelength difference between the even and odd transverse modes. For a $10 \mu \mathrm{m}$ ETR cavity, the 25th fundamental longitudinal mode has a mode separation of $100 \mathrm{~nm}$ at a wavelength of $2185 \mathrm{~nm}$. This is coincident with the lasing wavelength of the $2.1 \mu \mathrm{m}$ EEL structure utilized above, making it a promising structure for a single longitudinal mode ETR device operating at $2.1 \mu \mathrm{m}$.

Another important quantity that characterizes optical cavities is the quality factor $Q$, which is defined as the ratio of the amount of energy stored in the cavity in the form of a standing wave to the amount of energy lost during a round trip of the cavity. In laser cavities, the optical mode with the highest quality factor is favored for laser emission because of its low cavity loss. $Q$ factors for modes in an ETR cavity with a side length of $10 \mu \mathrm{m}$ are calculated based on the analytical field distribution and far-field emission [see Fig. 3(b).$^{11}$ These calculations show that the fundamental mode has much higher quality factors $\left(\sim 2 \times 10^{5}\right)$ than the first $\left(\sim 5 \times 10^{4}\right)$ and second $\left(\sim 3 \times 10^{4}\right)$ order modes. Higher order transverse modes in an ETR cavity experience higher cavity losses because they are only partially reflected from the cavity sidewall.

\section{ETR LASER DEVICE FABRICATIONS AND DEVICE CHARACTERIZATIONS}

The ETR laser processing started with wet etching to remove the InAs cap layer, followed by the deposition of a $300 \mathrm{~nm}$ thick $\mathrm{Si}_{3} \mathrm{~N}_{4}$ layer on the wafer to function as a hard mask for dry etching. The ETR pattern with a $10 \mu \mathrm{m}$ long side length and $1 \mu \mathrm{m}$ wide outcoupling waveguide is transferred onto the $\mathrm{Si}_{3} \mathrm{~N}_{4}$ layer using standard photolithography and reactive-ion etching (RIE). The patterned hard mask defined the ETR geometry for subsequent inductively coupled plasma (ICP) etching. The ICP etching recipe was optimized to attain a smooth surface and a vertical sidewall profile, and the ICP etching depth was $4 \mu \mathrm{m}$, close to the vertical pen-
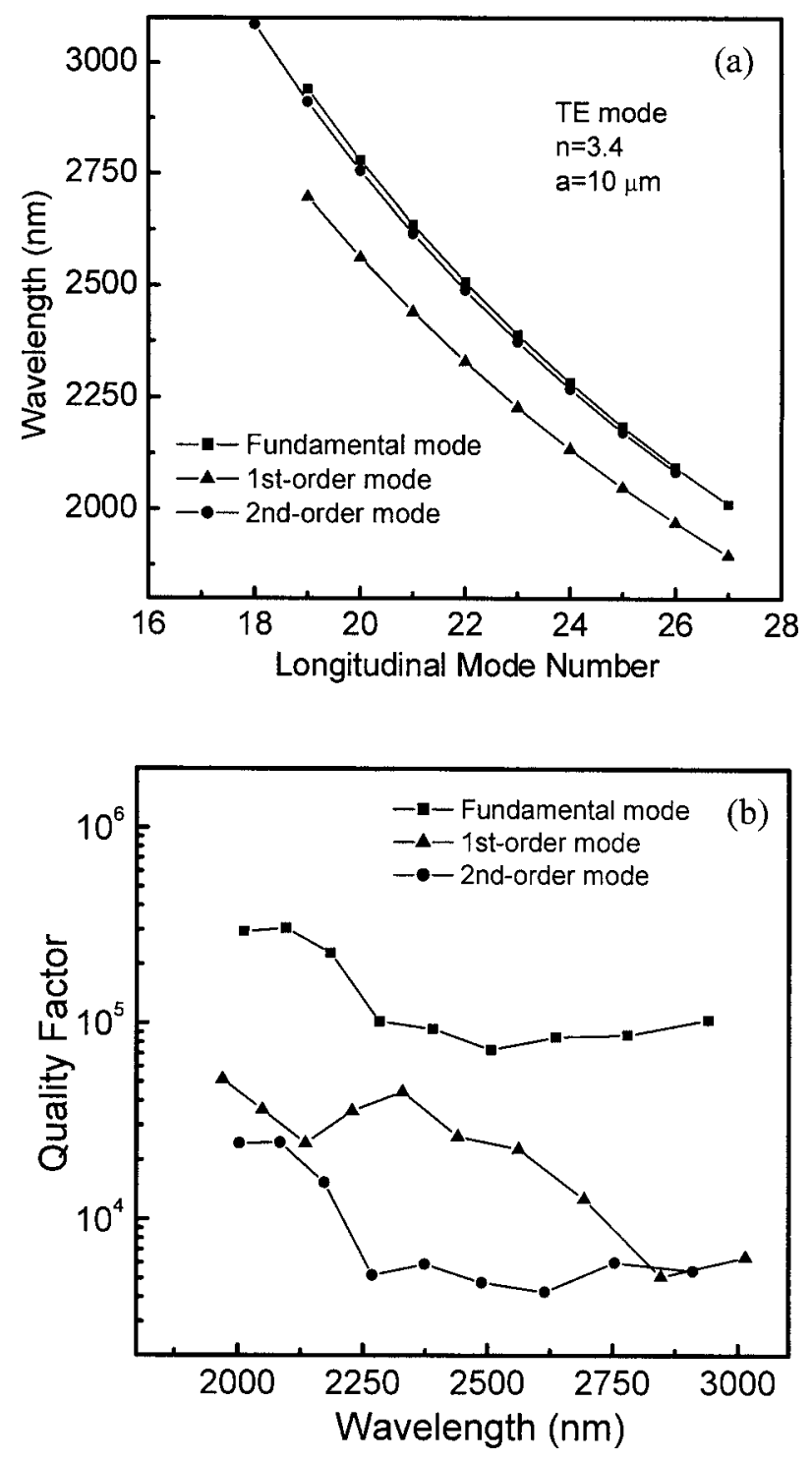

FIG. 3. (a) Calculated wavelength of the fundamental, first, and second order modes in a $10 \mu \mathrm{m}$ side length ETR. (b) Calculated $Q$ factors of the fundamental, first, and second order modes.

etration depth of the optical field of the confined modes. The equilateral triangle vertices were slightly rounded as a result of pattern distortion during photolithography. Next the residual $\mathrm{Si}_{3} \mathrm{~N}_{4}$ hard mask was removed using RIE, followed by the deposition of a $100 \mathrm{~nm} \mathrm{SiO}_{2}$ insulating layer, on which a contact window was opened on top of the ETR structure using wet etching. A top $\mathrm{Ti} / \mathrm{Pt} / \mathrm{Au} p$ contact was formed using standard metal deposition, and the wafer was lapped down to a thickness of $120 \mu \mathrm{m}$ after which a bottom $\mathrm{AuSn} / \mathrm{Ti} / \mathrm{Pt} / \mathrm{Au} n$ contact was deposited. These steps were followed by annealing at $300{ }^{\circ} \mathrm{C}$ for $30 \mathrm{~s}$ to form Ohmic contacts.

The fabricated midinfrared ETR laser device was cleaved across the outcoupling waveguide and characterized at $77 \mathrm{~K}$. Figure 4(a) shows the integrated spectrum intensity versus the injection current measured under $\mathrm{cw}$ operation. The current threshold is $0.5 \mathrm{~mA}$, which corresponds to 

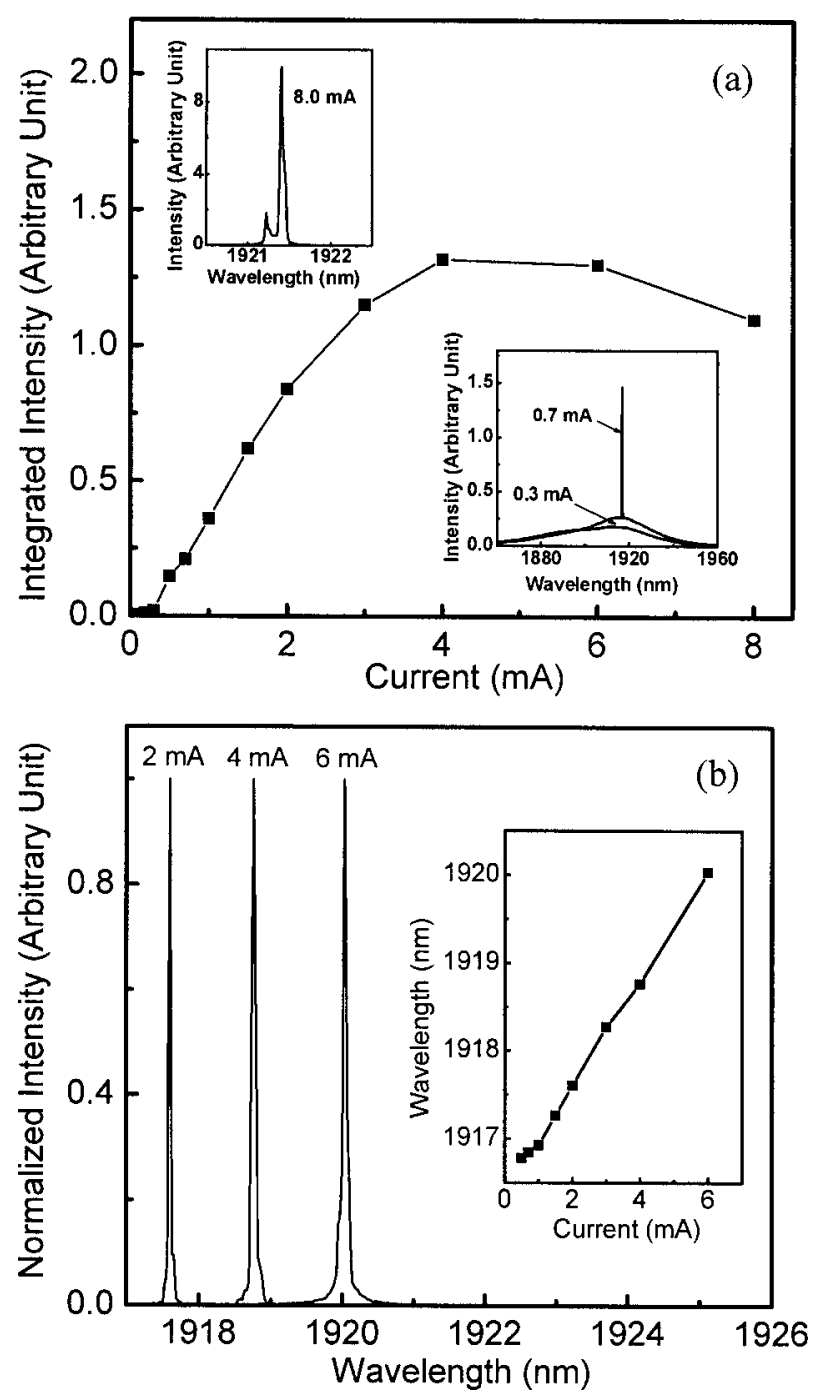

FIG. 4. (a) The integrated laser spectrum intensity vs injection current for a mid-IR ETR laser with a $10 \mu \mathrm{m}$ side length; bottom-right inset shows the laser spectrum just below threshold $(0.3 \mathrm{~mA})$ and just above threshold $(0.7 \mathrm{~mA})$; top-left inset shows the multimode laser spectrum under high injection. (b) Normalized laser spectra under different injection conditions; inset gives lasing wavelength vs injection current.

$J_{\text {th }}=1.2 \times 10^{3} \mathrm{~A} / \mathrm{cm}^{-2}$. Above threshold, the lasing intensity increases monotonically and starts to saturate around $4 \mathrm{~mA}$. The spectrum below threshold $(0.3 \mathrm{~mA})$ and above threshold $(0.7 \mathrm{~mA})$ is given in the bottom-right inset. At $0.3 \mathrm{~mA}$ a narrow electroluminescence spectrum is observed with a full width at half maximum (FWHM) of $53 \mathrm{~nm}$. As the injection current is increased to $0.7 \mathrm{~mA}$, single mode emission at $1916.84 \mathrm{~nm}$ appears with a FWHM of $0.74 \mathrm{~nm}$.

The single mode laser spectra under injection currents of 2.0, 4.0, and $6.0 \mathrm{~mA}$ are shown in Fig. 4(b). As the current increases, the lasing wavelength is tuned from 1916.78 to $1920.03 \mathrm{~nm}$, resulting in a continuous $3.25 \mathrm{~nm}$ single mode tuning range. The lasing wavelength shifts linearly with injection current (see inset) and is a consequence of thermal heating of the cavity caused by nonradiative recombination. Thermal heating results in an increase of the

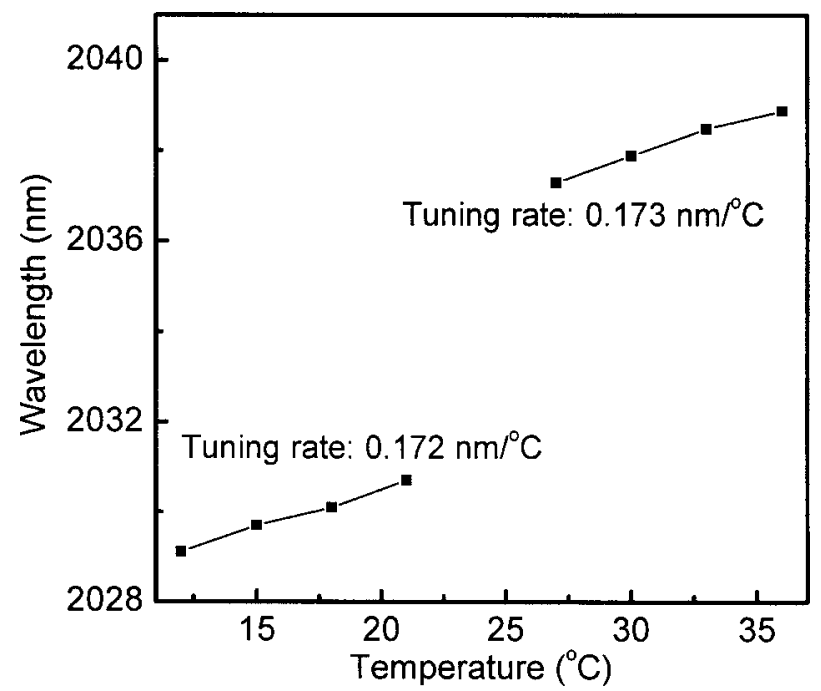

FIG. 5. Lasing wavelength tuning vs temperature for a short cavity device $(L=97 \mu \mathrm{m})$.

effective index of refraction and the thermal expansion of the ETR cavity, both of which increase the optical path length of the lasing mode. When the injection current is further increased to $8 \mathrm{~mA}$, the spectrum starts to show multimode behavior [see top-left inset of Fig. 4(a)].

\section{DISCUSSION}

In order to compare the wavelength tuning capability of an ETR laser with a short cavity laser, device A was cleaved to a short cavity length of $93 \mu \mathrm{m}$ and measured under quasi-cw operation (10\% duty cycle). At room temperature, the lasing spectrum near the threshold exhibited a single longitudinal mode with a FWHM of $0.78 \mathrm{~nm}$. The threshold current density of $850 \mathrm{~A} / \mathrm{cm}^{2}$ is much higher compared with a longer cavity device due to increased mirror loss and Auger recombination. The temperature dependent wavelength tuning (see Fig. 5) shows that this device has a free tuning range of $1.6 \mathrm{~nm}$, which is only half of that of the ETR laser.

The ETR lasers exhibit much higher threshold current densities compared to conventional EELs. The high threshold current density is mainly attributed to carrier losses at the ETR cavity facet interface which was formed using ICP etching. Studies reveal that devices fabricated on GaSb exhibit large leakage current, which is attributed to a residual native oxide layer on the GaSb surface as this material is highly chemically reactive with atmospheric oxygen, which can form native oxides several nanometers thick. An additional consequence of surface oxidation is the formation of elemental antimony at the oxide-GaSb interface, which creates a conduction channel parallel to the interface and leads to high surface leakage currents. Hence, suitable surface passivation is an important step for further development of GaSb midinfrared ETR lasers. Another type of carrier loss is caused by material damage at the surface. During ICP etching, semiconductor material is removed by the bombardment of high energy ions, which can potentially induce surface damage to the semiconductor material. These defects become carrier re- 
combination centers during laser operation. Surface damage is inevitable during ICP etching. However, it can be reduced by balancing the chemical and physical etching components with an optimized ICP etch recipe.

The high threshold current density is also attributed to the less than perfect geometric ETR cavity shape induced during the fabrication process. The operation of the ETR laser is based on the ETR geometric shape to provide total reflection and form a cavity. Because of processing limitations, it is difficult to get a perfect ETR cavity with smooth and vertical sidewalls. During fabrication, pattern distortions round the ETR vertices and leave less than perfectly straight sidewalls, which introduce additional optical losses in the ETR cavity. These pattern distortions are generated mainly in the photolithography process. The quality of the ETR cavity pattern can be further improved by utilizing advanced lithography techniques such as electron beam lithography.

The continuous, single mode tuning range of $3.25 \mathrm{~nm}$ is much smaller than the theoretically predicated $100 \mathrm{~nm}$ fundamental mode spacing. The high order transverse mode starts to appear when injection is only 16 times of threshold ( $8 \mathrm{~mA})$. This may be due to the reduced optical loss for higher order modes when the metal contact is deposited on the ETR sidewall. A simple solution for this problem would be to use a low refractive index polyamide to surround the ETR for planarization, while exposing the ETR top surface for metallization to maintain a metal-free sidewall as well as a uniform electrical injection.

\section{CONCLUSIONS}

High-quality $\mathrm{GaSb}$ based InGaAsSb/AlGaAsSb QW EELs with emission wavelengths from 2.1 to $3.1 \mu \mathrm{m}$ were grown, fabricated, and characterized. The $2.1 \mu \mathrm{m}$ device achieved $\mathrm{cw}$ operation up to $8.5 \mathrm{~mW}$ and a maximum operating temperature of $50^{\circ} \mathrm{C}$. By increasing the $\mathrm{QW}$ barrier $\mathrm{Al}$ mole fraction from $\mathrm{Al}_{0.25} \mathrm{Ga}_{0.75} \mathrm{As}_{0.02} \mathrm{Sb}_{0.98}$ to
$\mathrm{Al}_{0.40} \mathrm{Ga}_{0.60} \mathrm{As}_{0.03} \mathrm{Sb}_{0.97}$ in the $2.8 \mu \mathrm{m}$ devices, the hole confinement energy was increased from 15 to $82 \mathrm{meV}$, resulting in improved thermal performance and $\mathrm{cw}$ operation.

Calculations of the mode characteristics of a $10 \mu \mathrm{m}$ side length ETR cavity show that the 25th fundamental longitudinal mode has a mode separation of $100 \mathrm{~nm}$ at a wavelength of $2185 \mathrm{~nm}$ and that the fundamental mode has a much larger quality factor $\left(\sim 2 \times 10^{5}\right)$ than those of the first $(\sim 5$ $\left.\times 10^{4}\right)$ and second $\left(\sim 3 \times 10^{4}\right)$ order modes. Electrically injected, $10 \mu \mathrm{m}$ side length ETR lasers with $2.1 \mu \mathrm{m}$ emission achieved single mode, $\mathrm{cw}$ operation at $77 \mathrm{~K}$ with a $0.5 \mathrm{~mA}$ threshold current and a single mode tuning range of $3.25 \mathrm{~nm}$.

${ }^{1}$ P. L. Meyer and M. W. Sigrist, Rev. Sci. Instrum. 61, 1779 (1990).

${ }^{2}$ T. Töpfer, K. P. Petrov, Y. Mine, D. Jundt, R. F. Curl, and F. K. Tittel, Appl. Opt. 36, 8042 (1997).

${ }^{3}$ M. E. Webber, D. S. Baer, and R. K. Hanson, Appl. Opt. 40, 2031 (2001).

${ }^{4}$ V. Nagali, S. I. Chou, D. S. Baer, R. K. Hanson, and J. Segall, Appl. Opt. 35, 4026 (1996).

${ }^{5}$ A. Vicet, D. A. Yarekha, A. Perona, Y. Rouillard, S. Gaillard, A. N. Baranov, Spectrochim. Acta, Part A 58, 2405 (2002).

${ }^{6}$ G. W. Turner, H. K. Choi, and M. J. Manfra, Appl. Phys. Lett. 72, 876 (1998).

${ }^{7}$ J. G. Kim, L. Shterengas, R. U. Martinelli, G. L. Belenky, D. Z. Garbuzov, and W. K. Chan, Appl. Phys. Lett. 81, 3146 (2002).

${ }^{8}$ R. Werner, T. Bleuel, J. Hofmann, M. Brockhaus, and A. Forchel, IEEE Photonics Technol. Lett. 12, 966 (2000).

${ }^{9}$ S. L. McCall, A. F. J. Levi, R. E. Slusher, S. J. Pearton, and R. A. Logan, Appl. Phys. Lett. 60, 289 (1992).

${ }^{10}$ W. H. Guo, Y. Z. Huang, and Q. M. Wang, IEEE Photonics Technol. Lett. 12, 813 (2000).

${ }^{11}$ Y. Z. Huang, Q. Chen, W. H. Guo, Q. Y. Lu, and L. J. Yu, IEEE J. Sel. Top. Quantum Electron. 12, 59 (2006).

${ }^{12}$ Q. Y. Lu, X. H. Chen, W. H. Guo, L. J. Yu, Y. Z. Huang, J. Wang, and Y. Luo, IEEE Photonics Technol. Lett. 16, 359 (2004).

${ }^{13}$ C. Lin, M. Grau, O. Dier, and M. C. Amann, Appl. Phys. Lett. 84, 5088 (2004).

${ }^{14}$ M. Grau, C. Lin, O. Dier, C. Lauer, and M.-C. Amann, Appl. Phys. Lett. 87, 241104 (2005). 